\title{
Review Article \\ Perspectives for Titanium-Derived Fillers Usage on Denture Base Composite Construction: A Review Article
}

\author{
Nidal W. Elshereksi, ${ }^{1,2}$ Mariyam J. Ghazali, ${ }^{1}$ Andanastuti Muchtar, ${ }^{1}$ and Che H. Azhari ${ }^{1}$ \\ ${ }^{1}$ Department of Mechanical \& Materials Engineering, Faculty of Engineering \& Built Environment, \\ Universiti Kebangsaan Malaysia (UKM), 43600 Bangi, Selangor, Malaysia \\ ${ }^{2}$ Department of Dental Technology, College of Medical Technology, P.O. Box 1458, Misurata, Libya
}

Correspondence should be addressed to Che H. Azhari; husna.azhari@gmail.com

Received 8 February 2014; Revised 15 June 2014; Accepted 15 June 2014; Published 2 July 2014

Academic Editor: Krishnan Jayaraman

Copyright (c) 2014 Nidal W. Elshereksi et al. This is an open access article distributed under the Creative Commons Attribution License, which permits unrestricted use, distribution, and reproduction in any medium, provided the original work is properly cited.

Poly(methyl methacrylate) (PMMA) is an extensively used material in dentistry because of its aesthetics, processability, and reparability. However, PMMA is still far from being ideal in fulfilling the mechanical requirements of prosthesis. PMMA-based denture base polymers exhibit low fracture resistance and radiopacity behavior. Efforts to improve the mechanical and radiopacity properties of denture base materials through inclusion of silica-based fillers are ongoing. Although silane-treated siliceous fillers are commonly used, they are not sufficiently strong. They also exhibit cracks, which either cut through the glass fillers or propagate around the filler particles. This defect occurs when the dental composites are placed in aqueous oral environment because of the hydrolytic degradation of silica-based fillers and silane-coupling agents. The clinical problem of using silanes in adhesion promotion is bond degradation over time in oral environment. In addition, silanes do not bond effectively to nonsilica-based dental restorative materials. This review presents titanium-derived fillers as alternatives to siliceous fillers. Titanate-coupling agents are found to be effective couplers in treating Ti-based fillers because of their chemical compatibility and relatively high stability in aqueous environment.

\section{Introduction}

Polymers are important in dentistry because their distinctive properties allow a range of clinical applications, which are impossible with the use of other types of materials. The most widely used impression materials (alginates, polyethers, polysulfides, and silicones) are polymers. Further applications include denture bases, artificial teeth, cements, dies, provisional crowns, endodontic fillings, tissue conditioners, and pit and fissure sealants. Poly(methyl methacrylate) (PMMA) is extensively used as a denture base material [1]. However, this material is not ideal in every aspect, particularly in satisfying the mechanical requirements of prosthesis. Fracture of acrylic resin denture base occurs frequently because of fatigue and chemical degradation of base material [2].

Polymeric matrices with silane-treated silica-based fillers are commonly used in dental restorative materials $[3,4]$. However, these fillers do not exhibit sufficient strength to reinforce the resultant composites [4] and they leach in aqueous oral environment $[5,6]$. Siliceous filler treatment with silane-coupling agents provides bond between two components in dental composites, but this bond can be degraded by water absorbed by the composites $[4,6]$, thereby adversely affecting the mechanical properties of the materials and decreasing their longevity. Thus, incorporation of alternative fillers should be considered, in which a suitable coupling agent is used to achieve an acceptable mechanical behavior of the dental composites. This narrative review aims to evaluate the effectiveness of inclusion of titanium-derived fillers in dental composites and denture bases. Such fillers should be treated by a titanate-coupling agent because of its relatively good hydrolytic stability compared with that of silanes and the inefficiency of silanized nonsilica-based fillers $[7,8]$.

\section{A Brief Historical Review}

Early prostheses were fashioned by carving denture bases from naturally occurring materials, such as wood, bone, 


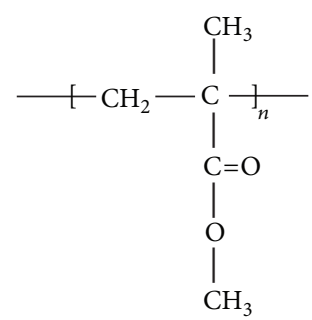

Figure 1: Chemical structure of PMMA.

and ivory; however, aesthetics and hygiene became the main concerns. In 1788, a porcelain complete denture was fabricated. Although this material was stable with minimal water absorption and solubility, as well as low porosity, it was brittle and difficult to grind and polish. During the middle of the 19th century, vulcanized rubber (vulcanite) was introduced as a denture base material. The main disadvantage of these denture bases was their dark red color, which was difficult to pigment, and absorption of saliva, making them unhygienic [1]. Moreover, vulcanite exhibited inherent massive volume shrinkage because of the vulcanizing techniques used at that time [3]. This material was eventually displaced by another polymer, PMMA (Figure 1), which displays improved physical, aesthetic, and handling properties [9]. The adoption of the dough technique first described in the mid-1930s enabled the use of acrylics in dentistry. In the dough technique, a liquid component (monomer) is mixed with a powder component (polymer). The monomer wets the polymer to a dough-like consistency, which is packed into the mould prior to polymerization. Adoption of the new denture bases was rapid in America. However, in Europe, change was forced upon the profession by rubber shortage during World War II. By the end of the war, the use of vulcanite for dentures had almost ceased. After the war, resins developed for aircraft production and the burgeoning plastics industry were offered for use as denture base materials; the simplicity of the dough technique and the lifelike results have sustained acrylics as the market leader to the present day [3].

\section{PMMA as a Denture Base Material}

Acrylic polymers were utilized as denture base materials since 1937 [9]. They were so well received by dental professionals that, by 1946 , approximately $98 \%$ of all denture bases were based on PMMA. The cured polymer should be stiff enough to hold the teeth in occlusion during mastication and to minimize uneven loading of mucus under the denture. The denture material should not creep under masticator loads for long-term use if good occlusion is to be maintained and potential irritant effects are kept at minimum [10]. Such material should also have sufficient strength and resilience to withstand normal masticator forces; withstanding sudden shock caused by impact forces is an important property. The material should not deteriorate in the aqueous environment of the mouth, and craze formation caused by solvents present in food, drinks, or medicaments should be absent or minimal [11].
TABLE 1: Composition of denture base materials (heat curing).

\begin{tabular}{lcl}
\hline \multirow{3}{*}{ Powder } & Polymer & PMMA \\
& Initiator & Benzoyl peroxide (BPO) $(0.5 \%)$ \\
& Pigments & Salts of cadmium or iron or organic dyes \\
\hline \multirow{3}{*}{ Liquid } & Monomer & MMA \\
& Crosslinking & Ethylene glycol dimethacrylate \\
& agent & (EGDMA) $(10 \%)$ \\
& Inhibitor & Hydroquinone $(>1 \%)$ \\
\hline
\end{tabular}

Acrylic resin is extensively used in denture construction. This material exhibits various desirable attributes and handling characteristics, such as low cost, lightweight, easy handling and processing, easy polishing, excellent aesthetics, lack of toxicity, and biocompatibility in the oral environment $[12,13]$. It is normally supplied in powder and liquid forms; details of its composition are given in Table 1. The major components of the powder are PMMA beads with diameters of up to $100 \mu \mathrm{m}$. These beads are produced by suspension polymerization, in which the methyl methacrylate (MMA) monomer containing an initiator is suspended as droplet in water. The temperature is then increased to decompose the peroxide and induce MMA polymerization to form PMMA beads that form a free-flowing powder at room temperature after drying. In addition, crosslinking molecules are added to reduce the formation of small surface cracks in the denture when it is allowed to dry. an inhibitor (hydroquinone) is used to prolong the shelf life of the liquid component.

3.1. Classification of Denture Base Polymers. Denture bases can be typically classified according to the activation method, which has a significant effect on the resultant material properties. During fabrication, the cure condition and method affect the physical and mechanical properties of the denture [14].

3.1.1. Heat-Cured PMMA. Table 1 summarizes the composition of heat-cured denture base. The powder supplied has significantly high molecular weight. The highest molecular weight distributions and lowest plasticizer content are favored because they produce better physical and mechanical properties in the cured denture base [3]. BPO is added as an initiator, which decomposes rapidly to form free radicals at $>65^{\circ} \mathrm{C}$. Once polymerization commences, the temperature of the resin may become considerably higher than the temperature of the water bath. the increase in the curing temperature enhances the mechanical and chemical properties of acrylic resins. The heat-cured PMMA is the strongest material for denture base fabrication $[15,16]$. In addition, this material has more color stability and less residual monomer level than light and autopolymerizing acrylic resins $[17,18]$. The heatactivated denture base can be modified with the inclusion of a rubber phase into the beads during polymerization, producing a high-impact acrylic denture base.

3.1.2. Cold-Cured PMMA. Cold-cured or self-curing PMMA is referred to as "pour risen" because it is poured into a processing mould made of agar hydrocolloid to form 
a denture base. The composition of this material is the same as that of the heat-cured version, with the following two differences: the powder contains polymer beads with lower molecular weight than those of the heat-cured material; the liquid contains a chemical activator (an amine molecular), which initiates the reaction. Self-curing or autopolymerizing denture bases are processed quickly at room temperature. They have more residual monomers ( $1 \%$ to $4 \%$ ) but lower dimensional changes $(0.2 \%)$ than heat-cured dentures [19].

The poured-type mould itself has design weaknesses. The gelatinous agar cannot grip the teeth as easily as does the rock-hard plaster mould. Thus, teeth displacement during acrylic pouring is likely to occur. In addition, prior to being placed in the mould, the teeth themselves are part of the wax-up. Thus, any wax remaining on the teeth prevents the monomer from wetting their surfaces. This problem is far less common when solution and diffusion of the wax can occur at elevated temperature of the heat-curing process.

\subsubsection{Light-Activated Polymer. Light-activated polymer is} a composite of a paste urethane dimethacrylate (UDMA) monomer with fillers. Although most of the light-curing composites are employed as direct filling materials [20], they could also be used as repair materials for prosthodontics and custom tray material. However, their application in denture construction is restricted when a patient has hypersensitivity to PMMA [21]. Some studies have shown that the properties of these denture polymers are slightly lower than those of the conventional PMMA materials and they produce slightly rougher surfaces that seem to stain more readily [19]. In addition, the adhesive strength of denture teeth to the lightcuring denture base is less than that of heat-curing denture base resins [22].

Light-cured materials are comparable with conventional heat-cured materials in terms of impact strength and hardness, but they have considerably lower elastic modulus. Thus, a denture based on light-cured material deforms elastically to a greater extent than a heat-cured denture under the forces of mastication. However, the transverse strength of light-cured material, which is a measure of the total force required to fracture a thin strip of material in a transverse direction, is just slightly lower than that inherent in conventional materials.

3.1.4. Microwave-Polymerized Polymers. The resins used with microwave-polymerized polymers have the same composition as those used with conventional material. The properties of the microwave resins are optimal when a special liquid is substituted for the normal monomer liquid. Although the denture base cures well in the special polycarbonate (instead of metal) flask with the use of normal monomer liquid, higher level of porosity is found compared with dentures processed with the use of special liquid. The properties and the accuracy of these materials are as good as or better than those of the conventional heat-cured material, and the processing time is significantly shorter ( $4 \mathrm{~min}$ to $5 \mathrm{~min}$ ) [19]. Lai et al. [23] concluded that microwave energy can efficiently polymerize denture base resin. High statistical differences are found in terms of morphology and flexural properties in favor of the water-bath method. In addition, the selection of appropriate microwave power and curing time is vital in reducing the porosity to a minimum level.

\section{Alternative Polymers}

Although PMMA has been commonly utilized in the fabrication of removable denture bases, a number of polymeric materials, such as high-density polyethylene (HDPE), polyamide (PA), and poly(L-lactide) (PLLA), have been studied for their prosthodontic applications. Furthermore, polystyrene polyvinyl acrylic and light-activated UDMA have also been used in the construction of denture bases. These materials must be durable and strong enough to withstand masticatory forces, particularly for patients with parafunctional habits. However, none of these polymers provides the unique combination of physical and aesthetic properties exhibited by PMMA. Thus, PMMA remained a main component of denture base polymer for many years because it is hard, rigid, and easy to repair and can be color-matched to the patient's teeth and gum tissue $[13,24]$. Moreover, Yilmaz and Korkmaz [25] stated that PMMA displays advantage for long-term fixed provisional restorations; it has higher fracture toughness values than poly(ethylene methacrylate) (PEMA) before and after reinforcement. In 2010, a comparative study between denture bases made from conventional PMMA and polyurethane denture base materials was performed by Young [26]. This study determined that samples of the alternative denture base material had relatively poor mechanical strength compared with the PMMA-based samples, which were all fabricated in accordance with the manufacturers' instructions. As a result, PMMA remained the dominant denture base material for $>50$ years, and a suitable alternative material has yet to be discovered.

Despite these excellent properties, improvement in the fracture resistance of PMMA is needed. Most denture fractures occur inside the mouth during service, primarily because of resin fatigue $[13,27]$. The denture base resin is subjected to various stresses, including compressive, tensile, and shear forces, during function. Some of the factors responsible for denture fracture include stress intensification, increased ridge resorption leading to an unsupported denture base, deep incisal notching at the labial frena, sharp changes at the contours of the denture base, deep scratches, and induced processing stresses. A modified PMMA that includes poly urethane (PU) rubbery particles shows higher fracture toughness than unmodified PMMA; however, its transparency is reduced [28]. Jagger et al. [2] conducted a study to strengthen and modify the acrylic resin by using graft copolymerization with high-impact resins. The resultant material was not generally evaluated because of flexural property deterioration of the resin. Moreover, resistance to functional loads and removal forces, which are mechanical factors, must be considered in choosing a provisional restorative material for clinical use [25]. Such properties can be developed effectively by creating a composite material. 


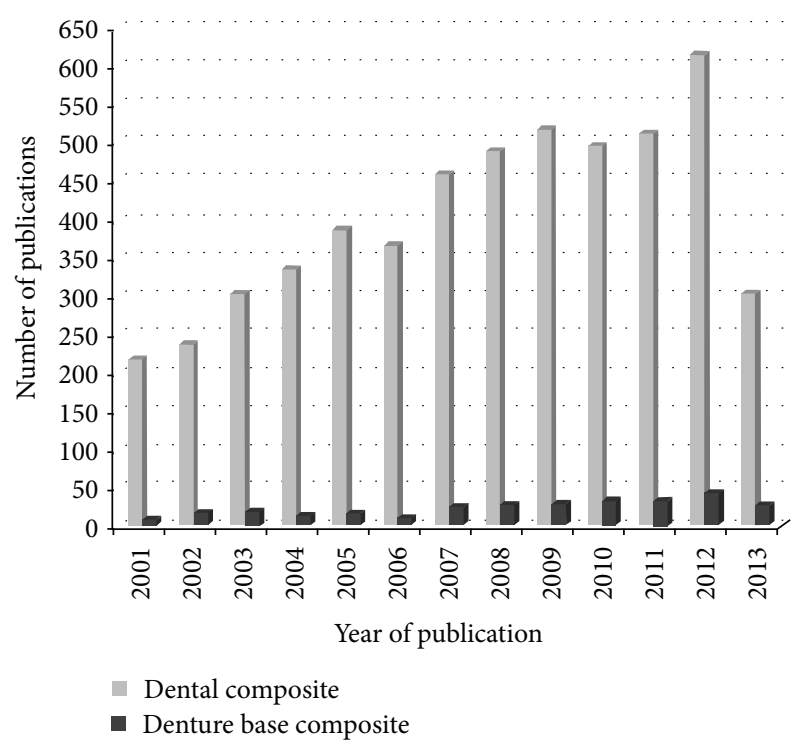

FIGURE 2: Increasing significance of dental composites compared with that of denture base composites. (Search keywords: dental composite and denture base composite in ISI Web of knowledge until October 2013).

\section{PMMA Composite as a Denture Base}

Polymeric composites are expansively utilized as dental filling and they have gained more significant attention than denture base composites (as shown in Figure 2). These materials are becoming increasingly popular for the treatment of smalland medium-sized defects in the posterior region because of their favorable physical properties. Composite filling materials were first developed in the early 1960s, and they provided materials with higher mechanical properties than acrylics and silicates, lower thermal coefficient of expansion, lower dimensional change on setting, and higher resistance to wear, thereby improving clinical performance [29]. The organic matrix employed is usually based on methacrylate chemistry, particularly crosslinking dimethacrylates, such as 2,2-bis[4-(2-hydroxy-3-methacryloyloxypropyl)phenyl]propane (Bis-GMA), ethoxylated Bis-GMA, 1,6-bis-[2-methacryloyloxyethoxycarbonylamino]-2,4,4-trimethylhexane (or UDMA), dodecanediol dimethacrylate, and triethylene glycol dimethacrylate [20]. Although Bis-GMA is used in most of the resin composite systems because of its superior aesthetic quality, simple operation technique, enhanced mechanical strength, less shrinkage, higher modulus, and reduced toxicity because of its lower volatility and diffusivity into the tissue, Bis-GMA still has some shortcomings, thereby limiting its application $[30,31]$.

In addition to the use of polymeric composite as dental filling material, PMMA composite is also used as bone cements [32-34], artificial teeth [35], and denture bases [13-15, 24, 35-37]. The differences in applications depend on the varying required characteristics. For instance, a significant development in dental filling composites is the ability to bond materials to tooth structure, whereas this property is not a requisite for materials used in removable prosthodontic construction. In other words, properties of denture base composites should be more related to their application, which make these two composites completely different. discrimination between them has been already stated in a previous study [38], in which a remarkable increase in fracture toughness with high pressure and temperature is shown in dental composite, whereas their effect on the mechanical properties of the PMMA denture base resin is unknown. Denture base composites have been developed to overcome the neat PMMA drawbacks, such as poor strength, polymerization shrinkage, and radiolucence. The denture base material should possess a desired balance of stiffness and toughness. The stiffness of the commercial denture base materials seems satisfactory; however, the inherently low fracture toughness of PMMA is a major shortcoming of its corresponding resins. Despite satisfying aesthetic demands, the mechanical requirements of prosthesis are unsatisfactory [37].

The fracture of acrylic resin dentures is still a common clinical occurrence. Attempts to analyze and determine the causes of such fractures have received considerable attention in recent years. These notable efforts have been conducted to solve this problem and to strengthen the dental polymer by incorporating various types of fibers [10, 13, 39-43] and fillers [24, 44-46] (Table 2), but it has not been solved [40]. In addition, denture breakage can also be caused by faulty design and/or faulty fabrication, such as severe frenal notch, prominent torus palatinus, poor fit of denture base, and also insufficient mechanical properties of the denture base resin, which lead to failure during service [27]. Denture fracture outside the mouth occurs from impact caused by accidents as a result of expelling the denture from the mouth while coughing or dropping the denture. Inside the mouth, excessive biting force may also cause fracture [47]. Although a strong positive association is found between fracture toughness and impact strength of PMMA bone cement [48], the fracture toughness method is more suitable than impact strength measurements in demonstrating the effects of resin modifications [49].

Furthermore, denture bases constructed from pure PMMA are not radiopaque, and thus they are not detectable on radiographs. This means that should such denture be accidentally inhaled or swallowed, it cannot be detected by radiographic means; any delay in localizing or removing the foreign body may be life threatening. Therefore, radiopacity in denture bases is a desirable attribute. Many attempts to incorporate a degree of radiopacity into acrylic denture base materials have been performed. Some radiopaque additives are mentioned in Table 2 accompanying remarkable comments according to the related references. Atoms with higher atomic number than $\mathrm{C}, \mathrm{H}$, and $\mathrm{O}$, which compose the acrylic resin, have been incorporated. A commercially available product contains $8 \% \mathrm{BaSiO}_{4}$, which did not produce sufficient levels of radiopacity. Increasing the $\mathrm{BaSiO}_{4}$ content to $29 \%$ produces sufficient radiopacity but shows deleterious effect on the mechanical properties of the resin; no additive has been proved to be satisfactory [26].

During clinical use, the denture base materials are immersed in saliva and, when not in use, may be soaked 
TABLE 2: Some of the components added into dental polymers.

\begin{tabular}{|c|c|c|}
\hline Additives & Comments & References \\
\hline \multirow{4}{*}{$\begin{array}{l}\text { Glass fibers, particles or } \\
\text { whiskers, quartz, and silica }\end{array}$} & Decreased mechanical properties after storage in water & Guo et al. 2012 [72] \\
\hline & Not strong enough & Lin et al. 2008 [64] and \\
\hline & Not radiopaque and not strong enough & Mirsasaani et al. $2011[4]$ \\
\hline & Reduced radiopacity & Cruvinel et al. 2007 [117] \\
\hline \multirow{2}{*}{ Polyethylene fibers } & \multirow{2}{*}{ Poor interaction between the fibers and the matrix } & Geerts et al. $2008[10]$ \\
\hline & & Alla et al. 2013 [13] \\
\hline $\begin{array}{l}\text { Ultrahigh molecular weight } \\
\text { polyethylene fibers }\end{array}$ & Impractical for the dental laboratory practice & Uzun et al. 1999 [42] \\
\hline Nylon fiber & Fiber pullout from the matrix & Lin et al. $2008[64]$ \\
\hline \multirow[t]{2}{*}{ Carbon and Kevlar fibers } & $\begin{array}{l}\text { Aesthetic unsatisfactory and poor adhesion with acrylic } \\
\text { resin }\end{array}$ & Tandon et al. 2010 [1] and Alla et al. 2013 [13] \\
\hline & $\begin{array}{l}\text { Complicated etching process required to improve their } \\
\text { incorporation into PMMA }\end{array}$ & Uzun et al. 1999 [42] \\
\hline \multirow[t]{2}{*}{$\begin{array}{l}\text { Metal wires and metallic } \\
\text { fillers }\end{array}$} & Poor adhesion between wires and the acrylic resin & $\begin{array}{l}\text { Mowade et al. } 2012 \text { [37] and Alla et al. } 2013 \\
\text { [13] }\end{array}$ \\
\hline & Aesthetic unsatisfactory & Young 2010 [26] \\
\hline $\begin{array}{l}\text { PA and sapphire whiskers, } \\
\text { fibers }\end{array}$ & Break up the homogeneity of acrylic resin & Mowade et al. 2012 [37] \\
\hline \multirow{2}{*}{$\mathrm{ZrO}_{2}$} & Not compatible with the matrix & Kitayama et al. 2009 [7] \\
\hline & Insufficient radiopacity & Carrodeguas et al. 2003 [33] \\
\hline $\mathrm{BaSO}_{4}$ & $\begin{array}{l}\text { Adverse effect on mechanical properties and color } \\
\text { instability }\end{array}$ & Young $2010[26]$ \\
\hline \multirow{3}{*}{$\begin{array}{l}\text { Comonomers containing } \\
\text { rubber phase }\end{array}$} & Increased cost & Mowade et al. 2012 [37] \\
\hline & Deterioration of flexural properties & Jagger et al. 1999 [2] \\
\hline & Reduction of the resin's translucency & Jung et al. 1998 [28] \\
\hline $\begin{array}{l}\text { Comonomers containing } \\
\text { heavy metals }\end{array}$ & Poor mechanical properties and aesthetic unsatisfactory & Young 2010 [26] \\
\hline
\end{tabular}

in water or cleansing agents. When immersed in such solutions, plasticizers and other soluble components may leach out over extended periods, whereas water or saliva is absorbed. The loss of plasticizer may cause brittleness and increased hardness. The effects of water on the bond strength of acrylic materials can have a detrimental effect on bond strength to acrylic resin. Furthermore, exposure of restorative materials to an aqueous environment is known to degrade their mechanical properties and resistance to wear. These deteriorations have been attributed to the hydrolytic degradation of the polymer matrix and filler, as well as to the water-induced filler-matrix bond failure [50, 51]. In other words, the used coupling agent is unaffected by an aqueous oral environment. numerous studies $[4-6,52]$ have indicated that the high water sorption and solubility of restorative resins produce decreased mechanical properties and reduced longevity of composite restorations.

\section{Interfacial Phase and Coupling Agents}

For a composite to have effective clinical performance, a good bond must form between the inorganic filler particles and the organic resin matrix during setting. This phenomenon is achieved through the use of coupling agents, such as silane [30]. This interfacial bonding is important to transfer load from the polymer matrix to the reinforcing fillers. The general principles of adhesion are mechanical interlocking and chemical bonding through ionic or covalent bonds, at the interface of composite's phases. However, if the adhesion is not durable enough and if any voids appear between the fiber and the matrix, then these voids may act as initial fracture sites in the composite, thereby facilitating material breakdown. Thus, durable adhesion between the fiber and the matrix is significant for the mechanical performance and the longevity of restoration in dental applications [53]. The most common types of coupling agents are organofunctional silanes and organotitanates, which are used to improve filler dispersion in matrix, prevent aggregation, and reinforce the interfacial coherence with resin [54].

6.1. Silane-Coupling Agents. Silanes are commonly used in dentistry in different applications to provide the opportunity for chemical bonding. They can bond both inorganic and organic dissimilar materials together. They typically contain two functional parts. One end contains an organic group that can polymerize with the adhered resin system. The other end contains groups that can react with inorganic groups of substrate, which means that silanes can function as mediators 


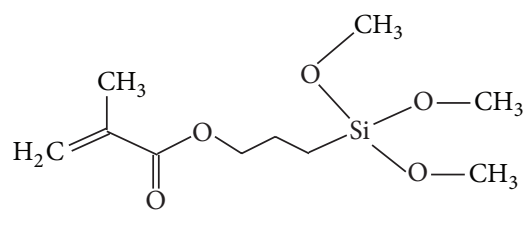

FIGURE 3: 3-Methacryloyloxypropyltrimethoxysilane silane-coupling agent.

between dispersed and organic phases. The most common silane, 3-methacryloyloxypropyltrimethoxysilane (MPS, or 3-MPS; Figure 3), has been evaluated as filler particles of resin composites and in lamination of glass fibers [55]. Silica and Si-based fillers are commonly employed fillers in dental composites [4, 26, 39] and biomaterials [56]; these additives can be easily functionalized by silanes because of the similarity in their ordered structure. Thus, silane-coupling agents chemically bond the silica, present in silica-based fillers such as porcelain, quartz, pyrogenic silicon dioxide, and silicate glasses [31,57], to the organic matrix of resin by means of siloxane bonds and hydrogen bond [55, 58]. Although the filler-matrix interphase is the least abundant phase of the composite material, it has significant effects on the physicomechanical properties of the composites $[59,60]$.

Good bond strength is found between a dental leucitebased glass ceramic and resin cement generated after functionalizing the ceramic filler with the use of silane-coupling agent [61]. Other studies $[62,63]$ demonstrated that flexural properties of PMMA containing silanized siliceous fillers could be improved effectively. The use of silane-treated silica fillers is an effective method of reinforcing PMMA resins. Despite the popularity of silica and glass fillers, they are not strong enough or they may create stress concentration points throughout the matrix caused by their irregular shapes, and then composites exhibit cracks, which either cut through the fillers or propagate around the filler particles $[4,26,56,64$, 65].

However, for nonsilica-based restorative materials, such as zirconia, metals, or metal alloys, the adhesion performance achieved with the use of silanes only is unsatisfactory [8]. These techniques do not improve the bond strength of zirconia and alumina ceramics because the suitable chemical reaction is impossible with these ceramics [7]. Approaches to solve this problem have been focused on surface conditioning. A currently used method is tribochemical silica coating. A silica-coated layer is anchored to the substrate surface such that silane-coupling agents can form durable bond with nonsilica-based materials through this layer [8]. Nevertheless, the qualitative and quantitative changes in the surface through these procedures are not fully known. In addition, failures are partly or mostly adhesive; that is, the failure is observed in the interface between resin composite and zirconia surface [66]. Kitayama et al. [7] reported that a tribochemical silica coating might be less effective for densely sintered ceramics than for glass-infiltrated ceramics. Moreover, a tribochemical silica coating cannot cover the entire abraded surface with silica. Therefore, long-term studies of the effects of various surface treatments are needed to improve our understanding of the bonding mechanisms and failure modes involved.

Dental restorative composites can serve in a wet environment, but they exhibit less stability in oral fluids. Although marked improvements have been noted in terms of physical and mechanical properties during the last two decades, various molecules, such as enzymes and alcohol, present in the oral cavity can degrade the composite and deteriorate the interfacial bond among the composite phases [4, 5, 67]. Thus, silane-coupling agents provide the bond between two components in dental composites, but this bond can be degraded by water absorbed by the composites. Hence, the improvements are more apparent when composites are exposed to high humidity and high temperature. In addition, the interface among composite constituents should not be degraded by the oral environment [67-69]. Some studies revealed that composites based on silane-coupling agents rapidly lose strength and stiffness when exposed to aqueous environment $[70,71]$, which could be attributed to tendency of silane-coupling agents to form aggregates on the filler surface, thereby resulting in an unstable bond between fillers and resin; this bond can be degraded by water absorbed by the composites [62]. Thus, their hydrolytic instability and longevity in oral conditions are a continuous concern for clinicians [69].

Guo et al. [72] reported that composites reinforced with silanized glass fibers exhibit decreased mechanical properties after prolonged storage in water. For example, the flexural strength and modulus of a commercial dental composite, which contains $38 \%$ short glass fibers, decrease by $66 \%$ and $60 \%$, respectively, after storage in water for three months. The flexural strength after dehydration did not recover to the same level as that in the dry group. Although some studies showed improved silane bond by applying an acetone primer to the glass prior to the silane treatment, this has not solved the problem of slow silane degradation in oral fluids [73, 74]. Accordingly, silanes should be replaced by one of other different kinds of coupling agents, particularly when nonsiliceous fillers are impregnated. For instance, zirconia ceramics are not silica based and thus they present a physicochemical challenge for reliable and durable resin bonding because chemically stable silica-silane bonds cannot be directly established [75]. Moreover, some composites cannot be light-cured, thereby limiting their application, because the mismatch of the refractive indices between the whiskers ( $\mathrm{SiC} 2.65$ and $\mathrm{Si}_{3} \mathrm{~N}_{4}$ 2.2) and polymer resin (1.53) causes high opacity of the whisker-reinforced composites. Therefore, alternative reinforcing elements for dental composites are also needed [72].

6.2. Titanate-Coupling Agents. As stated previously, the interfacial bond between dispersed and polymer composite's phases should not be deteriorated by the oral cavity moisture. In addition, silane provides chemical coupling by reacting with oxides or hydroxyl groups available on the particle surface, which are not available on the surface of other fillers [76]. Thus, a substitute for silane-coupling agents is necessary. Accordingly, titanate-coupling agents have important role in achieving durable bonding between ceramic filler and 
polymer matrix. They can modify the surface characteristics of filler and improve the interfacial bonding with the matrix. The nature of the interlayer between the filler and the polymer matrix, introduced by the titanate treatment, is significant in improving the mechanical properties of the composite [77]. Unlike silanes, titanium-derived coupling agents react with free protons at the inorganic interface, resulting in the formation of organic titanium monomolecular layers on the inorganic surface without water for condensation. The absence of a multimolecular layer at the interface and the chemical structure of titanates modify the surface energy of filler particles in such a way that the melt viscosities of polymers are lower than those of other types of coupling agent [78]. Titanate-coupling agents can also provide good interphase bonding, improve mechanical properties, enhance filler homogenous dispersibility, and modify the rheological behavior of the composites [22]. Titanates can also be used to couple interfaces, which are nonreactive with silane, such as calcium carbonate, graphite, aramid, and carbon black. They overcome many of the limitations of incompatible polymers and inorganic fillers [79].

Titanate-based coupling agents have been successful in providing chemical bonding and dispersion. The molecular formula is described as $\mathrm{XO}-\mathrm{Ti}-(\mathrm{OY})_{3}$, where $\mathrm{XO}$ - is the alkoxy group capable of reacting with the inorganic substrate and $-\mathrm{O} Y$ is the organofunctional fragment. The $Y$ portion typically contains several different groups to provide interaction with polar and nonpolar thermoplastics (e.g., benzyl and butyl), thermosets (e.g., amino and methacryl), and binder groups, such as pyrophosphato or carboxyl, which can introduce additional functions to the composite [76]. These coupling agents should protect the interface from hydrolytic deterioration. Hence, the coupling agents should provide water-resistant bonds at the interface. Organotitanates offer enhanced stability in wet environment. The hydrolytic stability of titanate coupler has been evaluated by a previous study, which stated that composite samples treated with titanates exhibit greater resistance to moistureingress than the untreated composites. Recovery in strength on reconditioning was also higher for treated samples than the control [80].

Tham et al. [24] reported that titanate-coupling agents can provide good interphase bonding, improve mechanical properties, enhance filler homogenous dispersibility, and modify the rheological behavior of the composites. In addition, titanate-coupling agents can be used to induce the hydrophobic property of filler surface characteristics and distribute the smaller particle size uniformly in polymer matrix [79]. When used in polymers, titanates can increase adhesion, impact strength, and mechanical properties [81]. An investigation of the effect of different coupling agents on the mechanical properties of the $\mathrm{TiO}_{2}$ particulate filled epoxy composite shows the mechanical properties enhanced with the use of titanate-coupling agent because of the formation of a strong interface or adhesion between the filler and matrix [82]. Titanate coupler is found to be more effective than silanecoupling agent, and it modifies the surface characteristics of filler and improves the interfacial bonding with the matrix [76, 82-84].

\section{Titanium-Based Fillers in Dentistry}

Titanium (Ti) and Ti-based alloys are preferred materials in the production of implants for medical and dental applications. These biomaterials have relatively poor tribological properties owing to their low degree of hardness. One approach to altering the biological properties of Ti alloys is by modifying its chemical composition. Another method is to produce a composite that exhibits the favorable mechanical properties of $\mathrm{Ti}$ and the excellent biocompatibility and bioactivity of a ceramic [56]. Furthermore, the introduction of Ti fillers as an added component can potentially enhance the mechanical strength and radiopacity of the dental filling composites [85]. Abdelaziz [86] reported that the type of the filler used significantly influences the properties of the composite restoratives. Although the improvement of the properties of dental composites has received considerable attention, the available information on the usage of $\mathrm{Ti}$ derived fillers remains limited.

In general, $\mathrm{TiO}_{2}$ particles are preferred in dentistry because of their pleasing color and high biocompatibility [44]. $\mathrm{TiO}_{2}$ nanoparticles $\left(n-\mathrm{TiO}_{2}\right)$ also have excellent mechanical properties; for example, the elastic modulus of $n-\mathrm{TiO}_{2}$ is approximately $230 \mathrm{GPa}$, and it is inexpensive with titanium being the fourth most abundant metal on earth, following aluminum, iron, and magnesium [87]. Other characteristics such as white color, low toxicity, and high stability and efficiency, as well as availability and low cost, have made $\mathrm{TiO}_{2}$ an appropriate antimicrobial additive for dental materials [88]. Considering that titania is stable in the body and does not degrade, bone cements that contain bioactive titania filler can thus be stable in the body. Subsequently, composite bone cement that contains $n-\mathrm{TiO}_{2}$ was developed. Studies have shown that certain compositions of the cement have good mechanical strength $[32,89]$.

Titania nanoparticles have been used as an additive in dental materials to match the opaque properties of teeth [90] and to enhance the mechanical properties of dental resins. Thorat et al. [91] prepared and characterized bis-GMA resin dental restorative composites with glass, silica, and titanium fillers. The researchers concluded that $\mathrm{TiO}_{2}$ fillers could be useful in future applications because their photocatalytic effects promote local antibacterial or remineralization reactions. Likewise, other studies have been performed to modify dental composites by incorporating $n-\mathrm{TiO}_{2}$ into a standard dental acrylic. Such studies have reported that the most available commercial product for dental restorations could be improved through the addition of $n-\mathrm{TiO}_{2}$ with relatively large particle size [85]. In addition, the mechanical behavior of $n-\mathrm{TiO}_{2}$ reinforced resin-based dental composites was investigated by Hua et al. [92]. This study demonstrated that the mechanical advantage of nanocomposites over microcomposites could be found in the reinforcing effect of $n-\mathrm{TiO}_{2}$ with $3 \%$ volume fraction on the stiffness, which is the same as a glass fiber with twice the volume fraction. This result is consistent with previous studies, which indicated that dental composites reinforced with $3 \% n-\mathrm{TiO}_{2}$ exhibited superior mechanical properties compared to the control, with minimal effects on flowability and radiopacity. Thus, these reinforced 
composites are promising materials for applications in dental restorations $[87,93,94]$.

Furthermore, a study [95] investigated the effect of the $\mathrm{BaTiO}_{3}$ filler on the fracture toughness of PMMA denture base polymer before and after soaking in simulated body fluid (SBF). The researchers concluded that when the composite was exposed to SBF, two detrimental effects occur. First, the liquid destroyed some filler-matrix bonds, resulting in an irreversible reduction in the fracture toughness. Second, the liquid caused the surrounding matrix to swell and plasticize, thus reducing the hoop stress around the filler particles and facilitating filler pull-out. In general, the fracture toughness of denture base materials was significantly changed after immersion in SBF. This change is attributed to the increase in the hydrolytic degradation of the silane-coupling agent, resulting in filler-matrix debonding. This result is consistent with the study of Deb et al. [96], which reported that water uptake can lead to the reduction in polymer strength. Elshereksi et al. [46] examined the thermal characterization of $\mathrm{BaTiO}_{3} / \mathrm{PMMA}$ denture base composites and found that the degradation temperatures of the filled samples were higher compared with that of the PMMA matrix. In addition, increasing filler content from $5 \mathrm{wt} \%$ to $20 \mathrm{wt} \%$ increased the degradation temperature and thermal stability of the resultant PMMA composites.

Modifying the surface of inorganic filler particles is essential because a durable bond must be created for the composite's phases. In an oral environment, the bonds among the resin composite silanized zirconia and $\mathrm{Ti}$ diminish over a long period. This decline may be due to the hydrolytic cleavage of siloxane bond in the siloxane interfacial layer [8]. Titanate couplers can be used to coat the inorganic fillers of dental materials to improve their dispersion and bonding with the resin matrix $[5,24]$. Moreover, a dramatic improvement in moisture resistance can be achieved by adding a small amount of titanates [80,97].

\section{Titanate-Treated Titanium-Based Fillers}

The selection of a proper coupling agent is important in prolonging longevity of the composite. Coupling agents such as phosphates and zirconates have been investigated for resin-to-zirconia bonding as an alternative to silane-coupling agents because of the enhanced bonding. Zirconium oxide nanoparticles are therefore surface functionalized with zirconates (as presented in Figure 4) or aluminozirconates [98]. The application of zirconate coupler and resin bonding agent mixture on the pure zirconium metal surface or zirconia has been shown to be effective in promoting the bonding between zirconium and $\mathrm{ZrO}_{2}$, as well as in dual-cured resin-luting cements $[98,99]$. Thus, chemical compatibility between the dispersed phase and the coupling agent should be considered. Some interfacial failures have been attributed to chemical incompatibility between the composite phases and the coupler [100]. When titanium-derived fillers are used, the titanate-coupling agent is found to be a better substitute for silane in achieving durable bonding between ceramic filler

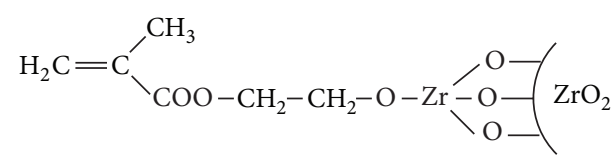

FIGURE 4: Zirconium oxide nanoparticles functionalized with methacryl zirconate.

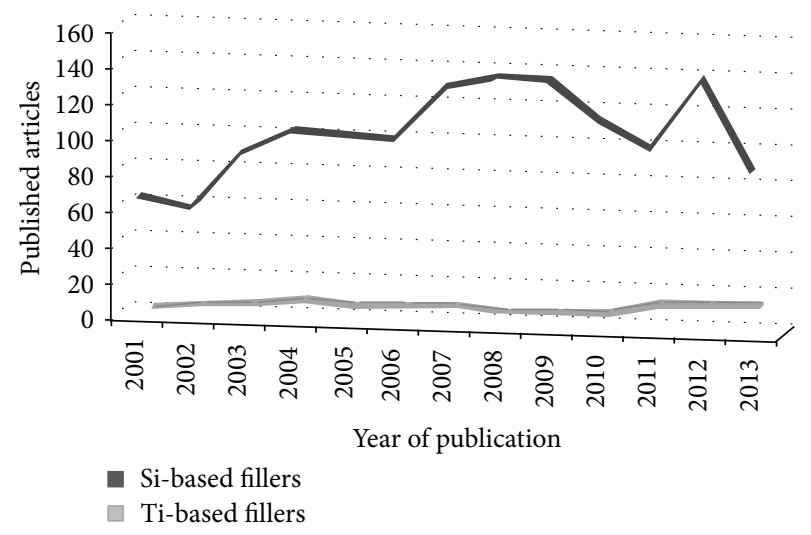

FIgUre 5: Popularity of Si-based fillers and limitation of Ti-based fillers usage in dental composites. (Search keywords: glass dental composite, Si dental composite, and Ti dental composite in ISI Web of knowledge until October 2013).

and polymer matrix. Promising results could be obtained with its application in restorative materials.

Compared with the use of titanium as dental implant material, the use of its derivatives is limited [101] (Figure 5). Titanium (Ti) is used in odontology because of its excellent characteristics, such as chemical inertia, low density, absence of toxicity, resistance to corrosion biocompatibility, and mechanical resistance. Such metals meet the existing requirements for use in oral defect restoration [102, 103]. Furthermore, $\mathrm{TiO}_{2}$ can also be utilized as a reinforcing agent in dental and biocomposite fabrication because of its antimicrobial properties and biocompatible features [88, 104, 105]. Khaled et al. [32] enhanced the mechanical properties of commercial acrylic cement by introducing novel nanostructured titania tubes $\left(n-\mathrm{TiO}_{2}\right.$ tubes) into the cement matrix. The results showed that the treatment with $1 \mathrm{wt} \% n-\mathrm{TiO}_{2}$ tubes results in significant increase in fracture toughness of PMMA composite. This increase is attributed to the enhanced interaction and strong interfacial adhesion between the treated $n-\mathrm{TiO}_{2}$ and polymer matrix, thereby allowing external mechanical stress to be more effectively transferred through the fillermatrix interface. These outcomes are similar to those in other studies $[44,106]$, which concluded that the dental composites filled with $\mathrm{TiO}_{2}$ exhibit high microhardness and mechanical strength. Moreover, compressive strength of composite with titanate-treated $\mathrm{TiO}_{2}$ was higher than that with untreated $\mathrm{TiO}_{2}$. The results suggested that $\mathrm{TiO}_{2}$ treated with titanatecoupling agent is useful as a pigment of the opaque material of fixed prosthodontic composite [107]. Regardless of the application, $\mathrm{Li}$ et al. [79] inferred that when $\mathrm{TiO}_{2}$ is treated with titanate-coupling agent, $\mathrm{TiO}_{2}$ exhibits a good modified surface. The surface characteristics of $\mathrm{TiO}_{2}$ change from 
hydrophilic to hydrophobic and $\mathrm{TiO}_{2}$ particles show good dispersion in liquid paraffin. The results indicated that treated $\mathrm{TiO}_{2}$ particles enhance binding force with and dispersion in polybutylene terephthalate matrix. Therefore, in such circumstances, titanate-coupling agent could be used as an alternative to the silanes.

In addition, another variety of titanium-derived fillers, such as $\mathrm{BaTiO}_{3}, \mathrm{SrTiO}_{3}$, and $\mathrm{ZrTiO}_{4}$, have not been used in biological application. Although $\mathrm{BaTiO}_{3}$ and $\mathrm{SrTiO}_{3}$ have been evaluated as formulated bone cement composites [33], $\mathrm{ZrTiO}_{4}$ is also applicable in bone tissue engineering [108]. These outcomes indicate a significant impact on the nomination of another material, such as $\mathrm{BaTiO}_{3}$ to be used as dental filler. $\mathrm{BaTiO}_{3}$, as a class of ceramic systems, possesses interesting features for biological applications because of its favorable mechanical [109], biocompatible [110-112], and piezoelectric properties, which extended the scope of biomaterials because of the stress-generated potential $[33,112]$. The piezoelectric effect is a property of certain materials in which an electrical potential is produced by the application of a mechanical stress. These potentials have been linked to the mechanical adaptation of bone in response to loading, thereby indicating that the addition of an electrically active component to an implant material may improve healing and adaptation of the surrounding tissue [113]. Although $\mathrm{BaTiO}_{3}$ fillers have repeatedly been shown to be biocompatible, no evidence of their dental applications has been found in literature. In addition, surface modification of $\mathrm{BaTiO}_{3}$ fillers by titanates has not been performed.

Radiopacity is another characteristic that should be considered. This feature is now considered as a desirable property of dental and biomaterials. All of the intraoral materials, including denture base materials, denture liners, direct filling restorative materials, and resin cement luting agents, are acknowledged to have desirable radiopacity [114]. As specified by the International Standards Organization (ISO 4049), the radiopacity of dental materials should be equal to or greater than the same thickness of aluminum wedge and should not be less than $0.5 \mathrm{~mm}$ of any value claimed by the manufacturer [115]. Radiopacity of composite materials should exceed that of dentin. However, no definitive maximum limit has been identified [93]. Research into radiopaque polymers focuses on developing methods to increase the average electron density and specific gravity of polymers by incorporating heavy elements into these systems. A common practice is to introduce radiopacity via radiopaque additives [116]. $\mathrm{BaTiO}_{3}$ filler can then be incorporated as a radiopacifier into PMMA matrix because of the relatively high atomic number of its components [95]. In addition, the radiopaque properties of a composite material highly depend upon the size, shape, amount of radiopacifying agent, and crystallinity of the radiopaque material. Thus, the radiopacity degree can vary within the same class of material. For instance, polymer composites intended for use in anterior teeth have filler particles that are smaller in size and lower in concentration than those intended for use in posterior teeth. In addition, the material thickness, the angulation of the Xray beam, the methodology employed for evaluation, the type of X-ray film, the age of developing and fixing solutions, and the alteration in the power/liquid ratio can affect material radiopacity [117].

\section{Conclusions}

Although PMMA is far from being a perfect denture base, it is the common material of choice for denture fabrication. PMMA exhibits low fracture resistance, particularly under fatigue failure inside the mouth and impact failure outside the mouth. Different polymers, such as HDPE, PA, PLLA, and PEMA, have been evaluated. However, the tests have not yielded new denture base polymers. Therefore, the expanded use of dental composites in a wide range of applications promotes the demand for the improvement of their properties and performance. This demand requires an ongoing investment in research and improvement. Silane-coupling agents have a critical function as mediators to fulfill the clinical requirements for durable adhesion among the composite phases. However, concerns about the hydrolytic instability and the effectiveness of silane-coupling agents on aqueous environment are frequently encountered, particularly when nonsilica fillers are impregnated in dental restorative materials. Moreover, titanate fillers may be important in enhancing dental composite properties when they are functionalized with the use of titanate-coupling agent.

\section{Conflict of Interests}

The authors declare that there is no conflict of interests regarding the publication of this paper.

\section{Acknowledgment}

The authors would like to thank the Department of mechanical and materials engineering, faculty of engineering and Built Environment, Universiti Kebangsaan Malaysia (UKM), for supporting this work.

\section{References}

[1] R. Tandon, S. Gupta, and S. K. Agarwal, "Denture base materials: from past to future," Indian Journal of Dental Sciences, vol. 2, no. 2, pp. 33-39, 2010.

[2] D. C. Jagger, A. Harrison, and K. D. Jandt, "The reinforcement of dentures," Journal of Oral Rehabilitation, vol. 26, no. 3, pp. 185-194, 1999.

[3] W. J. O'Brien, Dental Materials and Their Selection, Quintessence, Hanover Park, Ill, USA, 3rd edition, 2002.

[4] S. S. Mirsasaani, M. H. Manjili, and N. Baheiraei, "Dental nanomaterials," in Advances in Diverse Industrial Applications of Nanocomposites, B. Reddy, Ed., pp. 441-474, InTech, Rijeka, Croatia, 2011.

[5] K.-J. M. Söderholm, R. Mukherjee, and J. Longmate, "Filler leachability of composites stored in distilled water or artificial saliva," Journal of Dental Research, vol. 75, no. 9, pp. 1692-1699, 1996.

[6] M. Zhou, J. L. Drummond, and L. Hanley, "Barium and strontium leaching from aged glass particle/resin matrix dental composites," Dental Materials, vol. 21, no. 2, pp. 145-155, 2005. 
[7] S. Kitayama, T. Nikaido, R. Maruoka et al., "Effect of an internal coating technique on tensile bond strengths of resin cements to zirconia ceramics," Dental Materials Journal, vol. 28, no. 4, pp. 446-453, 2009.

[8] C. Y. K. Lung and J. P. Matinlinna, "Aspects of silane coupling agents and surface conditioning in dentistry: an overview," Dental Materials, vol. 28, no. 5, pp. 467-477, 2012.

[9] M. V. Kumar, S. Bhagath, and J. B. Jei, "Historical interest of denture base materials," Journal of Dental Sciences, vol. 1, no. 1, pp. 103-105, 2010.

[10] G. A. V. M. Geerts, J. Overturf, and T. G. Oberholzer, "The effect of different reinforcements on the fracture toughness of materials for interim restorations," Journal of Prosthetic Dentistry, vol. 99, no. 6, pp. 461-467, 2008.

[11] S. M. Lee, Advances in Biomaterials, Technomic, Lancaster, Calif, USA, 1987.

[12] T. G. Tihan, M. D. Ionita, R. G. Popescu, and D. Iordachescu, "Effect of hydrophilic-hydrophobic balance on biocompatibility of poly(methyl methacrylate) (PMMA)-hydroxyapatite (HA) composites," Materials Chemistry and Physics, vol. 118, no. 2-3, pp. 265-269, 2009.

[13] R. K. Alla, S. Sajjan, V. R. Alluri, and K. Ginjupalli, "Influence of fiber reinforcement on the properties of denture base resins," Journal of Biomaterials and Nanobiotechnology, vol. 4, pp. 91-97, 2013.

[14] S. H. Mohamed, A. M. Al-Jadi, and T. Ajaal, "Using of HPLC analysis for evaluation of residual monomer content in denture base material and their effect on mechanical properties," Journal of Physical Science, vol. 19, no. 2, pp. 127-135, 2008.

[15] M. G. Reeson and N. J. Jepson, "Achieving an even thickness in heat-polymerized permanent acrylic resin denture bases for complete dentures," The Journal of Prosthetic Dentistry, vol. 82, no. 3, pp. 359-361, 1999.

[16] R. N. Rached, J. M. Powers, and A. A. D. B. Cury, "Repair strength of autopolymerizing, microwave, and conventional heat-polymerized acrylic resins," The Journal of Prosthetic Dentistry, vol. 92, no. 1, pp. 79-82, 2004.

[17] N. Anil, C. Hekimoglu, and S. Sahin, "Color stability of heatpolymerized and autopolymerized soft denture liners," Journal of Prosthetic Dentistry, vol. 81, no. 4, pp. 481-484, 1999.

[18] C. V. Machado, C. B. Fortes, F. M. Collares, M. M. C. Forte, and S. M. W. Samuel, "Effect of different curing condition on material properties of acrylic resin for orthodontic appliances," Orthodontic Waves, vol. 69, no. 1, pp. 18-22, 2010.

[19] J. L. Ferracane, Materials in Dentistry; Principles and Applications, Lippincott Williams \& Wilkins, Philadelphia, Pa, USA, 2nd edition, 2001.

[20] S. W. Shalaby and U. Salz, Polymers for Dental and Orthopedic Applications, CRC Press, New York, NY, USA, 2007.

[21] N. Tanoue, K. Nagano, and H. Matsumura, "Use of a lightpolymerized composite removable partial denture base for a patient hypersensitive to poly(methyl methacrylate), polysulfone, and polycarbonate: a clinical report," Journal of Prosthetic Dentistry, vol. 93, no. 1, pp. 17-20, 2005.

[22] A. Palitsch, M. Hannig, P. Ferger, and M. Balkenhol, "Bonding of acrylic denture teeth to MMA/PMMA and light-curing denture base materials: the role of conditioning liquids," Journal of Dentistry, vol. 40, no. 3, pp. 210-221, 2012.

[23] C.-P. Lai, M.-H. Tsai, M. Chen, H.-S. Chang, and H.-H. Tay, "Morphology and properties of denture acrylic resins cured by microwave energy and conventional water bath," Dental Materials, vol. 20, no. 2, pp. 133-141, 2004.
[24] W. L. Tham, W. S. Chow, and Z. A. Mohd Ishak, "Effects of titanate coupling agent on the mechanical, thermal, and morphological properties of poly(methyl methacrylate)/hydroxyapatite denture base composites," Journal of Composite Materials, vol. 45, no. 22, pp. 2335-2345, 2011.

[25] C. Yilmaz and T. Korkmaz, "The reinforcement effect of nano and microfillers on fracture toughness of two provisional resin materials," Materials and Design, vol. 28, no. 7, pp. 2063-2070, 2007.

[26] B. C. Young, A comparison of polymeric denture base materials [M.S. thesis], University of Glasgow, Glasgow, UK, 2010.

[27] J. N. Arioli Filho, L. E. Butignon, R. D. P. Pereira, M. G. Lucas, and F. D. A. Mollo Jr., "Flexural strength of acrylic resin repairs processed by different methods: water bath, microwave energy and chemical polymerization," Journal of Applied Oral Science, vol. 19, no. 3, pp. 249-253, 2011.

[28] D.-W. Jung, S.-T. Noh, and Y.-W. Chang, "Toughening of PMMA with PU/PMMA composite particles," Journal of Industrial and Engineering Chemistry, vol. 4, no. 2, pp. 135-139, 1998.

[29] R. L. Sakaguchi and J. M. Powers, Craig's Restorative Dental Materials, Elsevier, Mosby, 13th edition, 2012.

[30] W. Lien and K. S. Vandewalle, "Physical properties of a new silorane-based restorative system," Dental Materials, vol. 26, no. 4, pp. 337-344, 2010.

[31] Z. Tarle, D. Marović, and V. Panduric, "Contemporary concepts on composite," Rad 514 Medical Sciences, vol.38, pp. 23-38, 2012.

[32] S. M. Z. Khaled, R. J. Miron, D. W. Hamilton, P. A. Charpentier, and A. S. Rizkalla, "Reinforcement of resin based cement with titania nanotubes," Dental Materials, vol. 26, no. 2, pp. 169-178, 2010.

[33] R. G. Carrodeguas, B. V. Lasa, and J. S. R. Barrio, "Injectable acrylic bone cements for vertebroplasty with improved properties," Journal of Biomedical Materials Research. Part B, vol. 68, no. 1, pp. 94-104, 2004.

[34] S. M. Zebarjad, S. A. Sajjadi, T. E. Sdrabadi, A. Yaghmaei, and B. Naderi, "A study on mechanical properties of PMMA/hydroxyapatite nanocomposite," Engineering, vol. 3, no. 8, pp. 795-801, 2011.

[35] R. Mosharraf and N. Mechanic, "Comparison of the effects of four pre-bonding preparation methods on the bond strength between a multilithic tooth and denture base resin," Dental Research Journal, vol. 4, no. 2, pp. 102-105, 2007.

[36] N. W. Elshereksi, S. H. Mohamed, A. Arifin, and Z. A. Mohd Ishak, "The environmental characterization and leachability of denture base poly (methyl methacrylate) filled barium titanate," Journal of Basic and Applied Science, vol. 1, pp. 23-30, 2007.

[37] T. K. Mowade, S. P. Dange, M. B. Thakre, and V. D. Kamble, "Effect of fiber reinforcement on impact strength of heat polymerized polymethyl methacrylate denture base resin: in vitro study and SEM analysis," Journal of Advanced Prosthodontics, vol. 4, no. 1, pp. 30-36, 2012.

[38] J. Nguyen, V. Migonney, N. D. Ruse, and M. Sadoun, "Resin composite blocks via high-pressure high-temperature polymerization," Dental Materials, vol. 28, no. 5, pp. 529-534, 2012.

[39] D. Vojvodić, F. Matejiček, Z. Schauperl, K. Mehulić, I. BagićČuković, and S. Šegović, "Flexural strength of E-glass fiber reinforced dental polymer and dental high impact strength resin," Strojarstvo, vol. 50, no. 4, pp. 221-230, 2008.

[40] J. Jancar, K. Hynstova, and V. Pavelka, “Toughening of denture base resin with short deformable fibers," Composites Science and Technology, vol. 69, no. 3-4, pp. 457-462, 2009. 
[41] S.-H. Yu, Y. Lee, S. Oh, H.-W. Cho, Y. Oda, and J.-M. Bae, "Reinforcing effects of different fibers on denture base resin based on the fiber type, concentration, and combination," Dental Materials Journal, vol. 31, no. 6, pp. 1039-1046, 2012.

[42] G. Uzun, N. Hersek, and T. Tinçer, "Effect of five woven fiber reinforcements on the impact and transverse strength of a denture base resin," The Journal of Prosthetic Dentistry, vol. 81, no. 5, pp. 616-620, 1999.

[43] T. K. Mowade, S. P. Dange, M. B. Thakre, and V. D. Kamble, "Effect of fiber reinforcement on impact strength of heat polymerized polymethyl methacrylate denture base resin: in vitro study and SEM analysis," Journal of Advanced Prosthodontics, vol. 4, no. 1, pp. 30-36, 2012.

[44] Y. Xia, F. Zhang, H. Xie, and N. Gu, "Nanoparticle-reinforced resin-based dental composites," Journal of Dentistry, vol. 36, no. 6, pp. 450-455, 2008.

[45] A. A. Zandinejad, M. Atai, and A. Pahlevan, "The effect of ceramic and porous fillers on the mechanical properties of experimental dental composites," Dental Materials, vol. 22, no. 4, pp. 382-387, 2006.

[46] N. W. Elshereksi, S. H. Mohamed, A. Arifin, and Z. A. Mohd Ishak, "Thermal characterization of denture base poly (methyl methacrylate) filled barium titanate," Journal of Physical Science. In press.

[47] H. D. Stipho, "Repair of acrylic resin denture base reinforced with glass fiber," The Journal of Prosthetic Dentistry, vol. 80, no. 5, pp. 546-550, 1998.

[48] G. Lewis and S. Mladsi, "Correlation between impact strength and fracture toughness of PMMA-based bone cements," Biomaterials, vol. 21, no. 8, pp. 775-781, 2000.

[49] G. Zappini, A. Kammann, and W. Wachter, "Comparison of fracture tests of denture base materials," The Journal of Prosthetic Dentistry, vol. 90, no. 6, pp. 578-585, 2003.

[50] L. Musanje and B. W. Darvell, "Aspects of water sorption from the air, water and artificial saliva in resin composite restorative materials," Dental Materials, vol. 19, no. 5, pp. 414-422, 2003.

[51] A. S. Kareem and R. H. Jehad, "An evaluation of water absorption of Giomer in comparison to other resin-based restorative materials," Journal of Baghdad College Dentistry, vol. 24, pp. 2528, 2012.

[52] S. B. Berger, A. R. M. Palialol, V. Cavalli, and M. Giannini, "Characterization of water sorption, solubility and filler particles of light-cured composite resins," Brazilian Dental Journal, vol. 20, no. 4, pp. 314-318, 2009.

[53] M. Zhang and J. P. Matinlinna, "E-glass fiber reinforced composites in dental applications," Silicon, vol. 4, no. 1, pp. 73-78, 2012.

[54] S. Bose and P. A. Mahanwar, "Effects of titanate coupling agent on the properties of mica-reinforced nylon-6 composites," Polymer Engineering \& Science, vol. 45, no. 11, pp. 1479-1486, 2005.

[55] J. P. Matinlinna and P. K. Vallittu, "Silane based concepts on bonding resin composite to metals," Journal of Contemporary Dental Practice, vol. 8, no. 2, pp. 1-13, 2007.

[56] M. U. Jurczyk, K. Jurczyk, K. Niespodziana, and A. Miklaszewski, "Titanium- $\mathrm{SiO}_{2}$ nanocomposites and their scaffolds for dental applications," Materials Characterization, vol. 77, pp. 99-108, 2013.

[57] P. Chaijareenont, H. Takahashi, N. Nishiyama, and M. Arksornnukit, "Effect of different amounts of 3-methacryloxypropyltrimethoxysilane on the flexural properties and wear resistance of alumina reinforced PMMA," Dental Materials Journal, vol. 31, no. 4, pp. 623-628, 2012.

[58] L. Wei, N. Hu, and Y. Zhang, "Synthesis of polymer-mesoporous silica nanocomposites," Journal of Materials, vol. 3, pp. 4066-4079, 2010.

[59] M. M. Karabela and I. D. Sideridou, "Synthesis and study of physical properties of dental light-cured nanocomposites using different amounts of a urethane dimethacrylate trialkoxysilane coupling agent," Dental Materials, vol. 27, no. 11, pp. 1144-1152, 2011.

[60] I. D. Sideridou and M. M. Karabela, "Effect of the amount of 3-methacyloxypropyltrimethoxysilane coupling agent on physical properties of dental resin nanocomposites," Dental Materials, vol. 25, no. 11, pp. 1315-1324, 2009.

[61] T. Hooshmand, J. P. Matinlinna, A. Keshvad, S. Eskandarion, and F. Zamani, "Bond strength of a dental leucite-based glass ceramic to a resin cement using different silane coupling agents," Journal of the Mechanical Behavior of Biomedical Materials, vol. 17, pp. 327-332, 2012.

[62] S. L. K. S. Naveen, M. G. J. P. Singh, M. Col, C. M. Viswambaran, R. K. Col, and C. R. K. Dhiman, "Evaluation of flexural strength of resin interim restorations impregnated with various types of silane treated and untreated glass fibres," Medical Journal Armed Forces India, 2012.

[63] M. M. Karabela and I. D. Sideridou, "Synthesis and study of properties of dental resin composites with different nanosilica particles size," Dental Materials, vol. 27, no. 8, pp. 825-835, 2011.

[64] S. Lin, Q. Cai, J. Ji et al., "Electrospun nanofiber reinforced and toughened composites through in situ nano-interface formation," Composites Science and Technology, vol. 68, no. 1516, pp. 3322-3329, 2008.

[65] S. K. Jun, D. A. Kim, H. J. Goo, and H. H. Lee, "Investigation of the correlation between the different mechanical properties of resin composites," Dental Materials Journal, vol. 32, no. 1, pp. 48-57, 2013.

[66] T. Heikkinen, Bonding of composite resin to alumina and zirconia ceramics with special emphasis on surface conditioning and use of coupling agents [M.S. thesis], University of Turku, Turku, Finland, 2011.

[67] M. Özcan, P. Alander, P. K. Valittue, M.-C. Huysmans, and W. Kalk, "Effect of three surface conditioning methods to improve bond strength of particulate filler resin composites," Journal of Materials Science: Materials in Medicine, vol. 16, no. 1, pp. 21-27, 2005.

[68] R. Lakes, "Composite biomaterials," in The Biomedical Engineering Handbook, D. J. Bronzino, Ed., chapter 41, pp. 1-13, CRC Press, New York, NY, USA, 3rd edition, 2006.

[69] J. P. Matinlinna, L. V. J. Lassila, and P. K. Vallittu, "The effect of three silane coupling agents and their blends with a crosslinker silane on bonding a bis-GMA resin to silicatized titanium (a novel silane system)," Journal of Dentistry, vol. 34, no. 10, pp. 740-746, 2006.

[70] C. M. Vaz, R. L. Reis, and A. M. Cunha, "Use of coupling agents to enhance the interfacial interactions in starch-EVOH/ hydroxylapatite composites," Biomaterials, vol. 23, no. 2, pp. 629-635, 2002.

[71] C. Schmidt and N. Ilie, "The mechanical stability of nanohybrid composites with new methacrylate monomers for matrix compositions," Dental Materials, vol. 28, no. 2, pp. 152-159, 2012.

[72] G. Guo, Y. Fan, J. Zhang, J. L. Hagan, and X. Xu, "Novel dental composites reinforced with zirconia-silica ceramic nanofibers," Dental Materials, vol. 28, no. 4, pp. 360-368, 2012. 
[73] M. Hashimoto, H. Ohno, M. Kaga, H. Sano, K. Endo, and H. Oguchi, "The extent to which resin can infiltrate dentin by acetone-based adhesives," Journal of Dental Research, vol. 81, no. 1, pp. 74-78, 2002.

[74] Y. Yoshida, K. Shirai, Y. Nakayama et al., "Improved filler-matrix coupling in resin composites," Journal of Dental Research, vol. 81, no. 4, pp. 270-273, 2002.

[75] P. Ntala, X. Chen, J. Niggli, and M. Cattell, "Development and testing of multi-phase glazes for adhesive bonding to zirconia substrates," Journal of Dentistry, vol. 38, no. 10, pp. 773-781, 2010.

[76] I. Kemal, A. Whittle, R. Burford, T. Vodenitcharova, and M. Hoffman, "Toughening of unmodified polyvinylchloride through the addition of nanoparticulate calcium carbonate and titanate coupling agent," Journal of Applied Polymer Science, vol. 127, no. 3, pp. 2339-2353, 2013.

[77] S. Bose and P. A. Mahanwar, "Effect of titanate coupling agent on the mechanical, thermal, dielectric, rheological, and morphological properties of filled nylon 6," Journal of Applied Polymer Science, vol. 99, no. 1, pp. 266-272, 2006.

[78] M. Hajian, G. A. Koohmareh, and A. Mostaghasi, "Investigation of the effects of titanate as coupling agent and some inorganic nanoparticles as fillers on mechanical properties and morphology of soft PVC," International Journal of Polymer Science, vol. 2011, Article ID 238619, 9 pages, 2011.

[79] G. Li, S. Fan, K. Wang, X. Ren, and X. Mu, "Modification of $\mathrm{TiO}_{2}$ with titanate coupling agent and its impact on the crystallization behaviour of polybutylene terephthalate," Iranian Polymer Journal, vol. 19, no. 2, pp. 115-121, 2010.

[80] N. Menon, F. D. Blum, and L. R. Dharani, "Use of titanate coupling agents in Kevlar-phenolic composites," Journal of Applied Polymer Science, vol. 54, no. 1, pp. 113-123, 1994.

[81] S. H. Han, H. J. Oh, H. C. Lee, and S. S. Kim, "The effect of post-processing of carbon fibers on the mechanical properties of epoxy-based composites," Composites Part B: Engineering, vol. 45, no. 1, pp. 172-177, 2013.

[82] M. Hussain, A. Nakahira, S. Nishijima, and K. Niihara, "Effects of coupling agents on the mechanical properties improvement of the $\mathrm{TiO}_{2}$ reinforced epoxy system," Materials Letters, vol. 26, no. 6, pp. 299-303, 1996.

[83] Y. W. Leong, M. B. A. Bakar, Z. A. M. Ishak, and A. Ariffin, "Effects of filler treatments on the mechanical, flow, thermal, and morphological properties of talc and calcium carbonate filled polypropylene hybrid composites," Journal of Applied Polymer Science, vol. 98, no. 1, pp. 413-426, 2005.

[84] S. Bose, H. Raghu, and P. A. Mahanwar, "Mica reinforced nylon-6: effect of coupling agents on mechanical, thermal, and dielectric properties," Journal of Applied Polymer Science, vol. 100, no. 5, pp. 4074-4081, 2006.

[85] K. D. Jandt, A. M. O. Al-Jasser, K. Al-Ateeq, R. W. Vowles, and G. C. Allen, "Mechanical properties and radiopacity of experimental glass-silica-metal hybrid composites," Dental Materials, vol. 18, no. 6, pp. 429-435, 2002.

[86] M. A. Abdelaziz, Synthesis of nanocomposites with nano- $\mathrm{TiO}_{2}$ particles and their applications as dental materials [M. Tech. Thesis], Cape Peninsula University of Technology, Cape Town, South Africa, 2012.

[87] J. Sun, A. M. Forster, P. M. Johnson et al., "Improving performance of dental resins by adding titanium dioxide nanoparticles," Dental Materials, vol. 27, no. 10, pp. 972-982, 2011.

[88] A. Sodagar, A. Bahador, S. Khalil, A. Saffar Shahroudi, and M. Zaman Kassaee, "The effect of $\mathrm{TiO}_{2}$ and $\mathrm{SiO}_{2}$ nanoparticles on flexural strength of poly (methyl methacrylate) acrylic resins," Journal of Prosthodontic Research, vol. 57, no. 1, pp. 15-19, 2013.

[89] K. Goto, M. Hashimoto, H. Takadama et al., "Mechanical, setting, and biological properties of bone cements containing micron-sized titania particles," Journal of Materials Science: Materials in Medicine, vol. 19, no. 3, pp. 1009-1016, 2008.

[90] B. Yu, J. S. Ahn, J. I. Lim, and Y. K. Lee, "Influence of $\mathrm{TiO}_{2}$ nanoparticles on the optical properties of resin composites," Dental Materials, vol. 25, no. 9, pp. 1142-1147, 2009.

[91] S. Thorat, N. Patra, R. Ruffilli, A. Diaspro, and M. Salerno, "Preparation and characterization of a BisGMA-resin dental restorative composites with glass, silica and titania fillers," Dental Materials Journal, vol. 31, no. 4, pp. 635-644, 2012.

[92] Y. Hua, L. Gu, and H. Watanabe, "Micromechanical analysis of nanoparticle-reinforced dental composites," International Journal of Engineering Science, vol. 69, pp. 69-76, 2013.

[93] M. Dafar, Reinforcement of flowable dental composites with titanium dioxide nanotubes [M.S. thesis], The University of Western, Ontario, Canada, 2014.

[94] K. Yoshida, M. Tanagawa, and M. Atsuta, "Effects of filler composition and surface treatment on the characteristics of opaque resin composites," Journal of Biomedical Materials Research, vol. 58, no. 5, pp. 525-530, 2001.

[95] N. W. Elshereksi, S. H. Mohamed, A. Arifin, and A. Z. Mohd Ishak, "Effect of incorporation on the fracture toughness properties of denture base poly(methyl methacrylate)," Journal of Physical Science, vol. 20, no. 2, pp. 1-12, 2009.

[96] S. Deb, M. Braden, and W. Bonfield, "Water absorption characteristics of modified hydroxyapatite bone cements," Biomaterials, vol. 16, no. 14, pp. 1095-1100, 1995.

[97] H. S. Kartz and J. V. Mileski, Handbook of Fillers for Plastics, Van Nostrand Reinhold, London, UK, 1987.

[98] K. Yoshida, Y. Tsuo, and M. Atsuta, "Bonding of dual-cured resin cement to zirconia ceramic using phosphate acid ester monomer and zirconate coupler," Journal of Biomedical Materials Research B, vol. 77, no. 1, pp. 28-33, 2006.

[99] K. Yoshida, M. Yamashita, and M. Atsuta, "Zirconate coupling agent for bonding resin luting cement to pure zirconium," The American Journal of Dentistry, vol. 17, no. 4, pp. 249-252, 2004.

[100] R. Roperto, M. Ghazy, O. El-Mowafy, and I. J. Pesun, "Effect of surface conditioning and resin cements on the adhesion of fiber posts," Journal of Dentistry \& Oral Health, vol. 1, pp. 1-5, 2013.

[101] A. Jokstad, U. Braegger, J. B. Brunski, A. B. Carr, I. Naert, and A. Wennerberg, "Quality of dental implants," International Journal of Prosthodontics, vol. 17, pp. 607-641.

[102] N. Adya, M. Alam, T. Ravindranath, A. Mubeen, and B. Saluja, "Corrosion in titanium dental implants: literature review," Journal of Indian Prosthodontist Society, vol. 5, no. 3, pp. 126131, 2005.

[103] G. A. A. Castilho, M. D. Martins, and W. A. A. Macedo, "Surface characterization of titanium based dental implants," Brazilian Journal of Physics, vol. 36, no. 3, pp. 1004-1008, 2006.

[104] Q. Cheng, C. Li, V. Pavlinek, P. Saha, and H. Wang, "Surfacemodified antibacterial $\mathrm{TiO}_{2} / \mathrm{Ag}^{+}$nanoparticles: preparation and properties," Applied Surface Science, vol. 252, no. 12, pp. 4154-4160, 2006.

[105] C. X. Cui, X. Gao, Y. M. Qi, S. J. Liu, and J. B. Sun, "Microstructure and antibacterial property of in situTiO2 nanotube layers/titanium biocomposites," Journal of the Mechanical Behavior of Biomedical Materials, vol. 8, pp. 178-183, 2012. 
[106] X. Miao, M. Zhu, Y. Li, Q. Zhang, and H. Wang, "Synthesis of dental resins using diatomite and nano-sized $\mathrm{SiO}_{2}$ and $\mathrm{TiO}_{2}$," Progress in Natural Science: Materials International, vol. 22, no. 2, pp. 94-99, 2012.

[107] K. Yoshida, H. Matsumura, T. Tanaka, and M. Atsuta, "Properties of titanium dioxide-polymer composite with titanate coupling agents," Shika Zairyo, kikai, vol. 8, no. 5, pp. 629-635, 1989.

[108] M. Mozafari, E. Salahinejad, V. Shabafrooz, M. Yazdimamaghani, D. Vashaee, and L. Tayebi, "Multilayer bioactive glass/zirconium titanate thin films in bone tissue engineering and regenerative dentistry," International Journal of Nanomedicine, vol. 8, pp. 1665-1672, 2013.

[109] J. Yu and J. Chu, "Nanocrystalline barium titanate," Encyclopedia of Nanoscience and Nanotechnology, vol. 6, pp. 389-416, 2004.

[110] G. Ciofani, L. Ricotti, C. Canale et al., "Effects of barium titanate nanoparticles on proliferation and differentiation of rat mesenchymal stem cells," Colloids and Surfaces B: Biointerfaces, vol. 102, pp. 312-320, 2013.

[111] F. R. Baxter, I. G. Turner, C. R. Bowen, J. P. Gittings, and J. B. Chaudhuri, "An in vitro study of electrically active hydroxyapatite-barium titanate ceramics using Saos-2 cells," Journal of Materials Science: Materials in Medicine, vol. 20, no. 8, pp. 1697-1708, 2009.

[112] F. R. Baxter, C. R. Bowen, I. G. Turner, and A. C. E. Dent, "Electrically active bioceramics: a review of interfacial responses," Annals of Biomedical Engineering, vol. 38, no. 6, pp. 2079-2092, 2010.

[113] Q. Wang, J. Liu, J. Zhu, Y. Ye, X. Li, and Z. Chen, "Piezoelectric and bonding properties of a cement-based composite for dental application," Applied Surface Science, vol. 255, no. 2, pp. 574-576, 2008.

[114] R. B. Fonseca, C. A. Branco, P. V. Soares et al., "Radiodensity of base, liner and luting dental materials," Clinical Oral Investigations, vol. 10, no. 2, pp. 114-118, 2006.

[115] International Organization for Standardization (ISO), "Dentistry-polymer-based filling, restorative and luting materials," ISO 4049:2000, Geneva, Switzerland, 2000.

[116] T. Tsuge, "Radiopacity of conventional, resin-modified glass ionomer, and resin-based luting materials," Journal of Oral Science, vol. 51, no. 2, pp. 223-230, 2009.

[117] D. R. Cruvinel, L. D. F. R. Garcia, L. A. Casemiro, L. C. Pardini, and F. D. C. P. Pires-de-Souza, "Evaluation of radiopacity and microhardness of composites submitted to artificial aging," Materials Research, vol. 10, no. 3, pp. 325-329, 2007. 

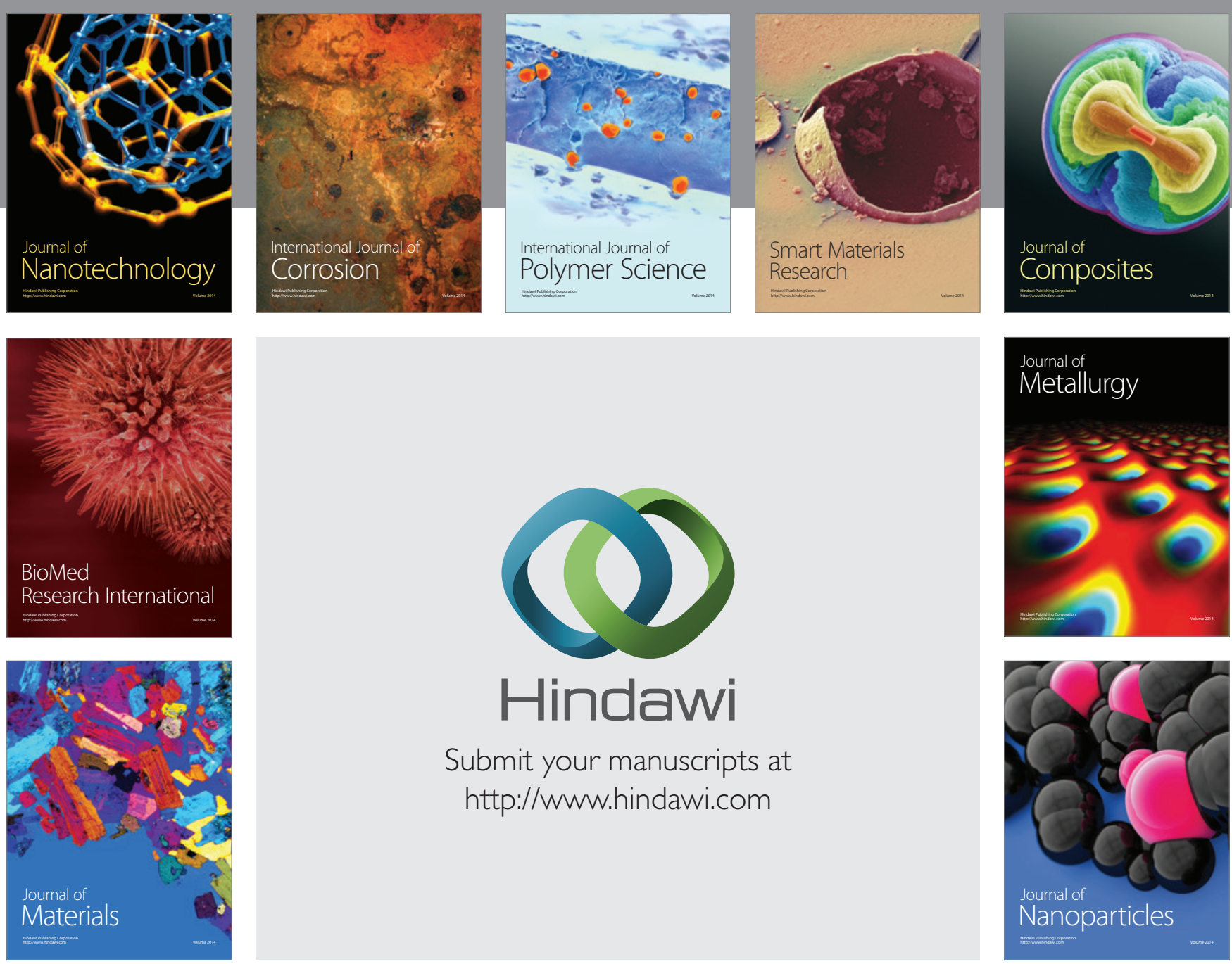

Submit your manuscripts at http://www.hindawi.com
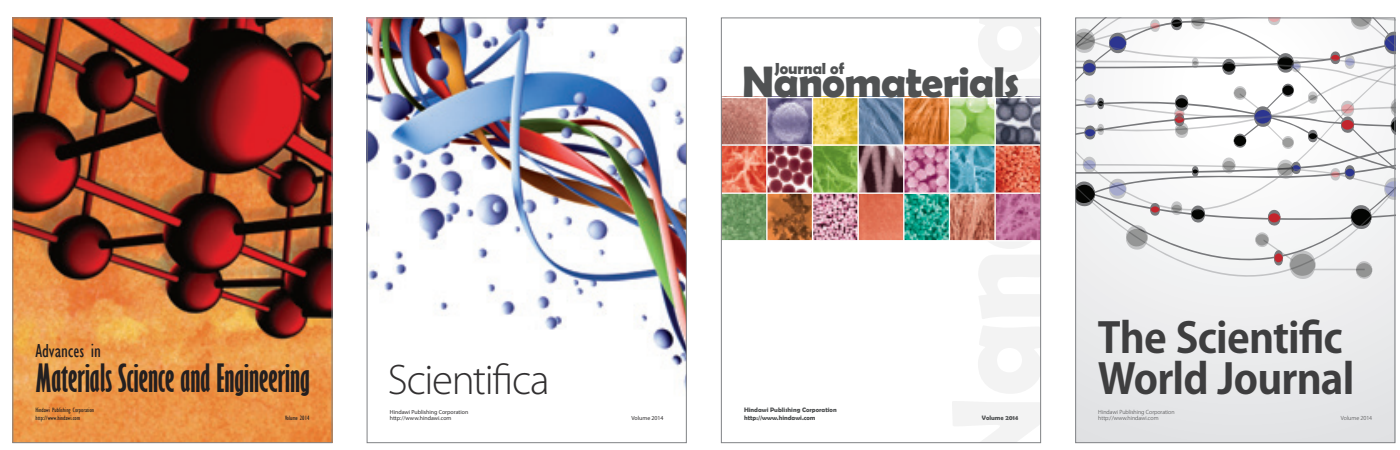

\section{The Scientific World Journal}
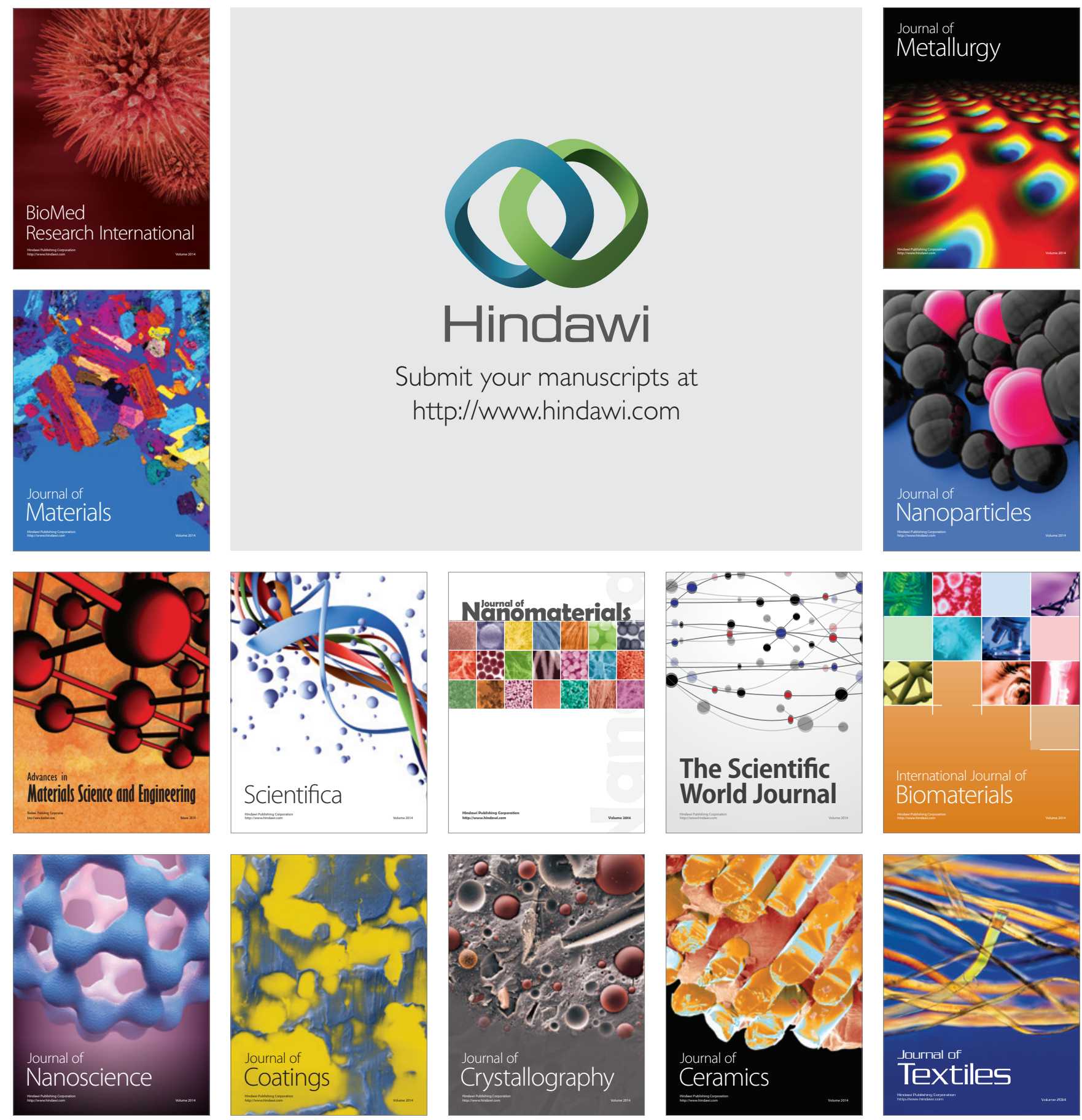